\title{
Deficiency in red blood cells
}

SIR - Glucose 6-phosphate dehydrogenase (G6PD) is a ubiquitous enzyme encoded by a gene that is highly polymorphic in humans ${ }^{1}$. Its deficiency is common in populations that have been subjected to selection by Plasmodium falciparum malaria ${ }^{2}$. Common variants entail the risk of acute haemolytic anaemia, but clinical expression of these variants is generally mild. By contrast, some

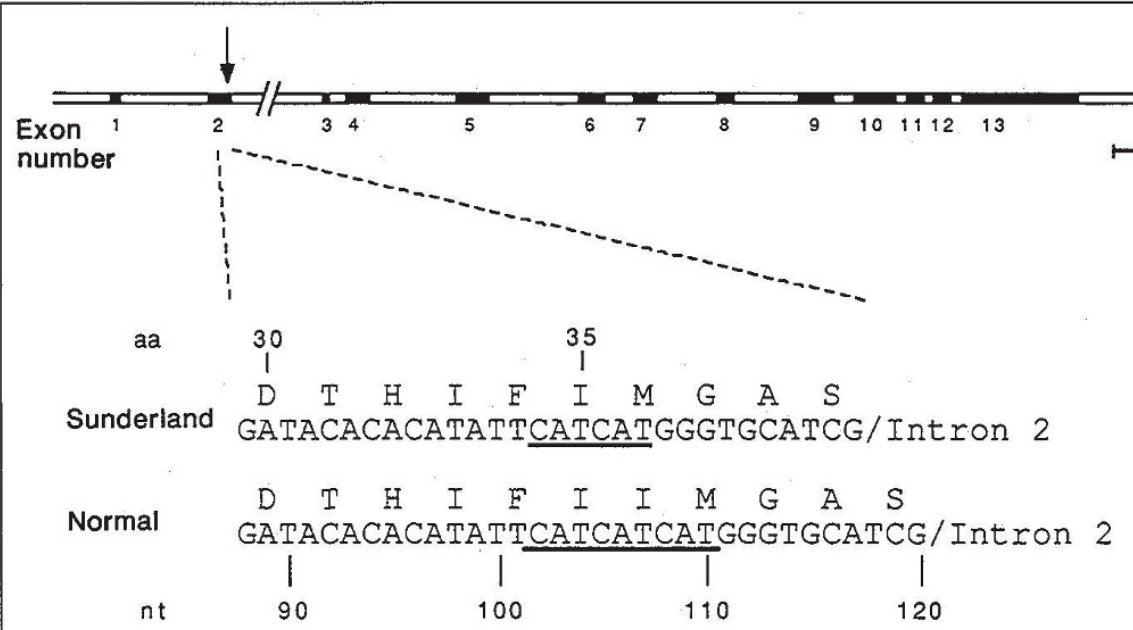

Genomic structure of the human G6PD gene (top). The break symbolizes the large intron II. The arrow indicates the position of the mutation in G6PD Sunderland. Scale bar, 200 base pairs. Below, Amino acid and nucleotide sequence of a portion of exon II of G6PD Sunderland and of normal human G6PD. Amino acid (aa) numbers are on top, and nucleotide (nt) numbers are at the bottom. Numbering is from the beginning of the translated sequence (see in ref. 7). The CAT repeats, one of which is deleted in G6PD Sunderland, are underlined.

individuals have rare variants associated with much more severe haemolysis ${ }^{3}$. The gene encoding G6PD has been mapped on the $\mathrm{X}$-chromosome in mammals, specifically on $\mathrm{Xq} 28$ in humans ${ }^{4}$.

Kanno et al. claimed ${ }^{5}$ that G6PD in red cells consisted of an amino-terminal region encoded by a gene on chromosome 6 , and of a carboxy-terminal region encoded by the $\mathrm{X}$-linked gene. In a News and Views article written at the time ${ }^{6}$, L.L. commented that, although several arguments could be made against the likelihood of such a fusion protein, formal genetic evidence for X-linkage of the amino-terminal region of G6PD was not available, because none of the mutations reported at the time ${ }^{7}$ mapped to that region. The claim by Kanno et al. has since been refuted by molecular analysis ${ }^{8,9}$ and attributed to a purification artefact ${ }^{10}$. Nevertheless, mutations in the amino-terminal region have still failed to turn up ${ }^{11}$.

Using a polymerase-chain-reaction based technique $^{12}$, we have now determined the nucleotide sequence of the entire coding region of the G6PD gene from a person with severe red cell G6PD deficiency and chronic haemolytic anaemia. The only abnormality we found was a three base-pair deletion in exon II (see figure), which predicts the loss of one of two adjacent isoleucine residues (amino acid 35 or 36), just upstream of the methionine residue called 'junctional' by
Kanno et al. This part of exon II would not be expressed in red cells if the claim of Kanno et al. had been correct. Our observation demonstrates that a mutation in this X-linked amino-terminal region of G6PD causes deficiency in red cells.

This new type of G6PD, which we designate G6PD Sunderland, is the first variant
found to result from a deletion rather than a

base change. The deletion is within a threefold CAT repeat, and has presumably arisen through misalignment at meiosis, with conservation of the reading frame.

Donald MacDonald MARGARET TOWN PHILIP MASON TOM VULLIAMY Lucio LuzzatTo

Department of Haematology,

Royal Postgraduate Medical

School,

Hammersmith Hospital,

London W12 ONN, UK

Royal Infirmary,

Sunderland SR2 TJE, UK

1. Luzzatto, L. \& Battistuzzi, G. Adv. hum. Genet. 14, 217-329 (1985)

2. Luzzatto, L. Blood 54, 961-976 (1979).

3. Luzzatto, L. \& Mehta, A. in The Metabolic Basis of Inherited Disease (eds Scriver, C. R., Beaudet, A. L., Sly, W. S. \& Valle, D.) 2237-2265 (McGraw-Hill, New York, 1989).

4. Pal, G. S., Sprenkle, J. A., Do. T. T., Mareni, C. E. \& Migeon, B. R. Proc. natn. Acad. Sci. U.S.A. 77, 2810-2813(1980) 5. Kanno, H., Huang, I.Y., Kan, Y. W. \& Yoshida, A. Cell 58, 595-606 (1989)

6. Luzzatto, L. Nature 341, 286-287 (1989).

7. Vulliamy, T. J. et al. Proc. natn. Acad. Sci. U.S.A. 85 , 5171-5175 (1988)

8. Mason, P. J., Bautista, J., Vulliamy, T. J., Turner, N. \& Luzzatto, L. Cel/62, 9-10 (1990).

9. Beutler, E., Gelbart, T. \& Kuhl, W. Cell62, 7-8 (1990).

10. Yoshida, A. \& Kan, Y. W. Cell 62, 11-12 (1990).

11. Beutier, E. Semin. Hemat, 27, 137-164 (1990)

12. Poggi, V., Town, M., Foulkes, N. S. \& Luzzatto, L Biochem. J. 271, 157-160 (1990).

\section{Sea-level constraints}

SIR - The authors of three important papers ${ }^{1-3}$ used Barbados coral cores of latest Pleistocene and Holocene ages to provide important constraints on sea-level fluctuations and to improve the radiocarbon timescale in this interval by calibrating it against the uranium-thorium timescale. The results of Bard et al. ${ }^{3}$, for example, indicate that the last deglaciation started about 3,000 years earlier when referenced to the $\mathrm{U}-\mathrm{Th}$ timescale than when referenced to the radiocarbon timescale. These authors suggest that this difference may explain the previously noted discrepancies between observations of sea-level change and models of glacial rebound in which ice sheets are considered only over Laurentia and Fennoscandia and that it is not necessary to introduce meltwater into the oceans from other ice sheets ${ }^{4-6}$.

This conclusion is incorrect. Time enters into the formulation in three ways: through the history of the changes in the ice sheets; through the observations of sea-level change and through the Earth's rheology. Provided the timescales are linear relative to each other and provided that the same timescale is used throughout, the use of either the U-Th or the ${ }^{14} \mathrm{C}$ timescale is immaterial. The results of Fairbanks ${ }^{1}$ indicate that the relation between the ${ }^{14} \mathrm{C}$ and $\mathrm{U}-\mathrm{Th}$ timescales is effectively linear for the past 20,000 years and that any departures from this linearity are small when compared with the uncertainties associated with many of the radiocarbon ages used to constrain ice models and sealevel change.

The ice models are almost wholly constrained by radiocarbon ages of debris left by the retreating ice front. In some instances in Fennoscandia, varve chronologies have been used; these should be reduced to the radiocarbon timescale. (This does not appear to have been done but there are only few varve dates so they are unlikely to distort the global ice-sheet models.) Observations of sea level have sometimes been related to varve or $\mathrm{U}-$ Th timescales, but the bulk of reported data refers to the conventional radiocarbon timescale. In the rebound modelling, the Earth's viscous time constraint(s) are usually considered as unknowns so that the viscosities will be either in $\mathrm{Pa}\left({ }^{14} \mathrm{C}\right) \mathrm{s}$ or $\mathrm{Pa}(\mathrm{U}-\mathrm{Th}) \mathrm{s}$, depending on which timescale is used for the other two inputs. (The distinction is not so insignificant if the two timescales differ by about 3,000 years after 20,000 years.)

If the U-Th timescale for the Barbados corals is used to constrain the glacialhydroisostatic rebound models then the ice models must be transformed to this timescale as well, with the result that the relation between observation and model prediction will be unchanged unless the relation between the two timescales is significantly nonlinear. One cannot usefully compare the U-Th 